\title{
Produção de commodities agrícolas na agricultura familiar: análise dos determinantes institucionais no norte mato-grossense
}

\author{
Commodities production in family farming: analysis of institutional \\ determinants in northern mato grosso
}

Marcos Rodrigues ${ }^{I}$, Indio Campos ${ }^{\text {II }}$

\begin{abstract}
RESUMO
Promover o desenvolvimento rural é um desafio para as políticas públicas, que podem ser promissoras ou ineficazes, pois envolvem diversas realidades e conceitos para o meio rural. Ao envolver a agricultura familiar, a problemática se mostra mais complexa, pois o arranjo de possibilidades produtivas é amplo. Este trabalho teve como objetivo analisar quais mecanismos permitem que a agricultura familiar se integre à produção de soja em Mato Grosso, desafiando os paradigmas existentes. Utilizando a Análise Fatorial Exploratória (AFE) foi possível elaborar um índice de inovação da agricultura familiar (IIAF). Os resultados demonstraram que para desenvolver a produção de soja, os agricultores familiares utilizam contratos de prestação de colheita que reduzem necessidades de investimento de longo prazo e contratos de crédito com tradings, suprindo demandas financeiras de curto prazo. Embora as inovações institucionais contribuam para a geração de renda familiar, elas mantêm o paradigma tecnológico baseado em economias de escala, portanto, limitam a entrada de agricultores familiares que não tenham capital, tecnologia e capacidade de adaptação aos requisitos da cadeia produtiva.
\end{abstract}

Palavras-chave: Análise Fatorial; Arranjos institucionais; Agronegócio; Soja

\begin{abstract}
Promoting rural development is a challenge for public policies that may be promising or ineffective, it involves dealing with diverse realities and concepts in rural areas. By involving family farming the problem become complex because of the broad possibilities in arrangement of productive units. This work aimed to analyze which mechanisms allow family farmers to integrate soybean production in Mato Grosso, challenging the actual paradigm. Exploratory Factor Analysis (EFA) was used to elaborate the index of technological and productive adhesion in family farming (IIAF). The results demonstrated that to develop soybean production, family farmers contract harvesting services that reduce their need for long-term investment and credit agreements with tradings that provide shortterm financial needs. Even tough institutional innovation contributes to family's income, it does not change the technological paradigm based in economies of scale, therefore, restricting the entrance of family farmers that do not possess capital, technology, and adaption to the supply chain requisites.
\end{abstract}

Keywords: Factorial Analysis; Institutional arrangements; Agribusiness; Soybean

\footnotetext{
I Universidade Federal Rural da Amazônia (UFRA) - marcos.rodrigues.adm@gmail.com

II Universidade Federal de Mato Grosso (UFMT) - indiocmps@gmail.com
} 


\section{INTRODUÇÃO}

O Brasil se destaca mundialmente na produção rural como um todo pela alta produtividade e produção dos agentes em diversas culturas (soja, milho, algodão, cana-de-açúcar, laranja, café, entre outras). Sendo o agronegócio um setor estratégico nacional, respondendo por cerca de $20 \%$ do Produto Interno Bruto (PIB) em 2016 (CEPEA/ESALQ, 2017). Tal expressividade é demonstrada pelos números destas atividades, a soja, principal commodity nacional para exportação teve produção total de 115 milhões de toneladas na safra 2018/2019 (CONAB, 2020).

Neste cenário encontra-se o estado de Mato Grosso, um dos principais representantes no agronegócio brasileiro, seja pela sua grande produção, seja pela liderança nas inovações tecnológicas e institucionais no campo. $O$ estado foi na safra $2016 / 2017$ o maior produtor nacional de soja ( $26,7 \%$ da produção nacional), de milho ( $29,5 \%$ da produção nacional) e de algodão ( $66 \%$ da produção nacional), além de deter o maior rebanho bovino (13,88\% das cabeças em 2016$)$ no país (CONAB, 2020; IBGE, 2020). Estes dados indicam a importância do setor agrícola e pecuário mato-grossense nacionalmente.

Entretanto, o estado é marcado por uma definição da estrutura agrária na produção de soja em unidades rurais. Esta atividade estabelece um paradigma produtivo modernizante baseado em elevada aplicação de capital em investimento fixo e semifixo, e uso de padrões produtivos de alto custo que reduzem as margens de lucro (PLOEG et al., 2000), formando o denominado pacote tecnológico (VANDER VENNET; SCHNEIDER; DESSEIN, 2016; WESZ, 2016) que requer a prática de economias de escala como mecanismo de viabilizar a produção de soja.

Consequentemente a agricultura familiar, por deter uma reduzida quantidade de área frente ao número de propriedades rurais, acabou excluída do processo de integração de mercados agrícolas com características modernizantes - processo este que se fortaleceu a partir da década de $1990 \mathrm{com}$ a liberalização da economia e redução da participação do setor público sobre a agricultura - (BELIK; PAULILLO, 2009). Em Mato Grosso, segundo os dados do Censo Agropecuário 2017, a agricultura familiar embora representasse $68,8 \%$ dos estabelecimento rurais, ocupava apenas 9,3\% da área rural (IBGE, 2017). Esta realidade estabelece barreiras para adoção de economias de escala, sendo requisito para cultivo da soja.

O agronegócio integra muitos agentes ao processo de produção, sendo um destes agentes a agricultura familiar. Velocidade e pretensão em adotar novas tecnologias são necessárias dentro do agronegócio de commodities (ADENLE; MANNING; AZADI, 2017). Como colocado por alguns autores, para a agricultura familiar se integrar ao mercado, requer-se que estes produtores rurais adotem padrões produtivos previamente estabelecidos pelas cadeias produtivas (ABRAMOVAY, 2007). Portanto, fica estabelecido um desafio para a agricultura familiar, pois estas unidades de produção muitas vezes são desprovidas não apenas de área agricultável, mas também de capital e recursos humanos qualificados para se adequarem a tais exigências.

Neste sentido, para os agricultores familiares integrarem aos mercados que exigem elevada aplicação de capital e tecnologia como a produção de commodities agrícolas, necessitando identificar as possibilidades que surgem do ambiente institucional e desenvolver inovações (institucionais) dentro de suas estruturas de governança, permitindo a superação do paradigma produtivo modernizante 
tradicional. A inovação não deve ser entendida apenas como o desenvolvimento de novas tecnologias capazes de aumentar a produtividade, mas também se refere a mudanças institucionais (KLERKX; AARTS; LEEUWIS, 2010), que alteram a forma de organização do mercado, das transações e das práticas de produção, logo criam meios alternativos para adaptação dos agentes em um determinado mercado com características definidas.

A produção familiar de soja, principalmente no Cerrado, possui alto potencial de crescimento, o que pode beneficiar a geração de renda de diversas famílias. Entretanto, levantam-se questões sérias sobre a sustentabilidade, haja visto que tal atividade pode comprometer a conservação das florestas nativas, devido à pressão por expansão de novas áreas (DEFRIES et al., 2010; DUCHELLE et al., 2014; FEARNSIDE, 2001), no qual afetar o ecossistema e biodiversidade local devido ao uso intensivo de biocidas (GOULSON et al., 2015) ou mesmo com impacto direto na saúde humana (BERGER; ORTEGA, 2010). Embora possa se mostrar uma alternativa viável economicamente, a produção de soja necessita desenvolver mais mecanismos para garantir a sustentabilidade.

Neste contexto estabeleceu-se como objetivo deste estudo analisar as inovações institucionais que permitem a inserção da agricultura familiar do Norte de Mato Grosso na cadeia produtiva da soja. A hipótese aqui elaborada é de que o acesso dos agricultores à cadeia produtiva de commodities, em especial a de soja, se viabiliza por dois conjuntos de práticas institucionais (regras formais e/ou informais que se desenvolvem ao longo da cadeia produtiva) que ocorrem simultaneamente: 0 primeiro sendo a prática de prestação de serviços de colheita, que permite a redução do investimento e o segundo são práticas contratuais que garantem acesso a recursos de custeio e comercialização da produção.

\section{METODOLOGIA}

\section{1 Área amostral e coleta dos dados}

Foi realizado o levantamento de dados na região Norte de Mato Grosso através uma pesquisa de campo nos municípios de Ipiranga do Norte, Itanhangá, Nova Ubiratã, Sinop, Vera e Tabaporã com aplicação de questionários estruturados com agricultores familiares que produzem soja na região Norte de Mato Grosso. A região Norte de Mato Grosso é propícia a expansão da soja em unidades familiares haja visto a consolidação desta atividade na região Central do estado em décadas anteriores, que já praticam a atividade baseada no paradigma produtivo modernizante.

A amostra foi determinada a partir do levantamento de quantos agricultores familiares que produziram soja em 2006 (censo agropecuário mais recente à época), que somavam 387 (IBGE, 2006), utilizando uma significância de 5\% e margem de erro de $10 \%$. Entretanto, devido a diferença temporal entre o Censo Agropecuário e a pesquisa (que ocorreu em 2016) juntamente com o fato de muitos agricultores apenas arrendarem suas áreas para outros realizarem cultivo (fato não captado pelo censo), foi possível levantar dados com 72 produtores rurais através da aplicação de questionários. Considera-se agricultor familiar àquele produtor que atende os requisitos expostos na Lei $11.326 / 2006$, artigo 30, sendo: i) área até quatro módulos 
fiscais; ii) renda predominante de atividades desempenhadas na propriedade; iii) mão-de-obra predominantemente familiar e iv) gestão familiar do empreendimento.

O questionário aplicado aos produtores rurais familiares era composto por 30 questões subdivididas em três blocos: a) Características do produtor, onde foram mensurados características demográficas, como idade, sexo, estado civil, entre outras; b) Características da propriedade, para mensuração das condições fundiárias e acesso tecnológico da propriedade e; c) Características da produção, na qual são levantadas as características produtivas, tecnológicas e institucionais da produção de commodities, como produtividade, preço venda, formas de financiamento, acesso a maquinário, contratos, financiamentos.

\subsection{Análise fatorial exploratória}

Para verificar como os mecanismos institucionais e tecnológicos permitem a agricultura familiar o cultivo da soja, foi conduzida a Análise Fatorial Exploratória (AFE) através da extração de fatores por meio do método dos componentes principais. O objetivo da extração é reduzir o número de variáveis a uma escala menor (fatores) que são altamente correlacionados, possibilitando a identificação de novas relações entre as variáveis (HAIR et al., 2014). O modelo de análise fatorial pode ser escrito na forma matricial conforme a Equação 1 (BARTHOLOMEW et al., 2008)

\section{Sendo}

$$
X=\alpha F+\epsilon
$$

$X=$ Vetor de variáveis observáveis $\left(x_{1}, x_{2}, \ldots, x_{i}\right)$;

$\alpha=$ Matriz (i, q) de constantes desconhecidas (cargas fatoriais);

$F=$ Vetor de variáveis latentes -fatores-,$\left(f_{1}, f_{2}, \ldots, f_{q}\right) ; q<i$;

$\epsilon=$ Denota os resíduos;

Foram selecionadas para o modelo de análise fatorial dez variáveis. As variáveis selecionadas representam as características que compõem a produção (lucro safra 2014/2015, área total plantada de soja em 2014/2015, recursos próprios para custeio da safra 2014/2015, possui colheitadeira própria), condições pessoais (total de receitas não agrícolas em 2015, idade), inovações e contratos (fornece para o programa de biodiesel, contratou Pronaf Mais Alimentos, valores de vendas antecipadas, contratou 'pacote' (PR-). Todas as variáveis selecionadas descrevem o comportamento da produção agrícola de soja, verificando a relação da produção com economias de escala (lucro, área e capital), inovação (contratos) e conhecimento (idade) e estão descritas na Tabela 1.

Tabela 1 - Descrição das variáveis utilizadas na Análise Fatorial Exploratória.

\begin{tabular}{lc}
\hline Variável & Nomenclatura \\
\hline Lucro safra 2014/2015 & LS \\
Área total plantada de soja em 2014/2015 & AT \\
Recursos próprios para custeio da safra 2014/2015 & RP \\
Possui colheitadeira própria & CP \\
Total das receitas não agrícolas em 2015 & RNA \\
Idade do produtor rural & ID \\
Fornece para o programa de biodiesel & BIO \\
Contratou Pronaf Mais Alimentos & MA
\end{tabular}


Valores de vendas antecipadas

Contratou CPR (pacote)

VA

Fonte: Elaboração do autor, 2017.

Nota: A Cédula de Produto Rural (CPR), instituída pela Lei no 8929, de 22 de agosto de 1994, é um mecanismo que permite a antecipação de recursos ao produtor rural na forma de insumos mediante pagamento futuro com produto. Alguns agricultores denominam tal instrumento como pacote, por envolver insumos pré-estabelecidos que formam um pacote tecnológico padronizado.

A consistência geral do modelo de análise fatorial foi realizada pelo teste de Kaiser-Meyer-Olkin (KMO). Os valores superiores a 0,5 são recomendáveis para manter a consistência do modelo. $O$ teste de esfericidade de Bartlett também foi utilizado para medir a adequação do modelo de análise fatorial (TIMM, 2002). A extração dos fatores foi realizada com a análise de componentes principais com a técnica da raiz latente, selecionando os autovalores $(\lambda)$ maiores do que 1 . A rotação ortogonal dos fatores foi realizada com o critério VARIMAX. As cargas fatoriais rotacionadas foram utilizadas para determinar em qual fator cada variável é alocada, foi determinada a maior carga fatorial absoluta para associar a variável a um fator.

Além da obtenção dos fatores foi estimada a matriz de escores fatoriais $\left(E F_{i}\right)$ por meio da regressão de Thomson, que busca minimizar o quadrado médio do erro (ESTABROOK; NEALE, 2013). Os escores fatoriais são medidas computadas para cada fator para cada sujeito da amostra (HAIR et al., 2014). A função dos escores fatoriais será a elaboração do Índice de Inovação da Agricultura Familiar (IIAF), a ser abordado a seguir.

\section{3 Índice de Inovação da Agricultura Familiar (IIAF)}

A partir dos escores fatoriais foi possível a construção de um índice que busca representar o grau tecnológico e produtivo da agricultura familiar norte matogrossense na produção de soja. O Índice de Inovação da Agricultura Familiar (IIAF) utilizou o resultado individual nos escores fatoriais normalizados em uma escala de zero à um -Equação 2-. Tal metodologia foi proposta por Santana (2007), onde permitiu o mesmo classificar o desempenho competitivo de empresas de polpa de frutas. A equação foi adaptada, mantido um peso constante para cada fator, diferentemente do proposto por Santana (2007). Esta metodologia também foi utilizada por Amaral et al (2019) na piscicultura da Amazônia.

Sendo:

$$
I I A F_{i}=\frac{\sum_{j=1}^{q} E F_{i j}}{q}
$$

$E F_{i j}=$ Escores fatoriais para cada observação para cada fator; $j=1,2 \ldots, q$;

$q=$ Número de fatores obtidos pela análise de componentes principais;

Agricultores familiares com maior IIAF correspondem àqueles com maior capacidade de geração de renda devido às tecnologias e inovações utilizadas na propriedade, o que acabam por também resultar em maior capacidade de geração de renda. Ao contrário, índices menores tentem a refletir o baixo grau produtivo da propriedade, com baixa utilização tecnológica e de inovação nos métodos de gestão. 


\subsection{Variáveis de influência no IIAF}

A construção do IIAF permite classificar os produtores familiares conforme a sua adesão tecnológica e resultado produtivo em uma escala No entanto, também se faz necessário determinar quais variáveis (características da produção agrícola e familiar) que estão mais ligadas a este índice e que impactam positivamente ou negativamente em sua composição.

Para alcançar este objetivo foi estimado um modelo de regressão linear através do método dos Mínimos Quadrados Ordinários (MQO) considerando o IIAF como a variável dependente e um conjunto de variáveis independentes constantes na Tabela 2. O modelo consta na Equação 3. As variáveis selecionadas representam as características do setor de soja em Mato Grosso, sendo a receita da produção a relação com preços e produção; custos com arrendamento de máquinas e receitas com biodiesel efeitos de inovações institucionais; receita de fontes não agrícolas representam o peso que outras atividades tem sobre a dedicação com a produção rural e a contratação de CPR como mecanismo para cobertura de custos de produção.

Tabela 2 - Variáveis ${ }^{1}$ utilizadas como repressores na estimação do modelo econométrico.

\begin{tabular}{llc}
\hline Variável & Tipo & Nomenclatura \\
\hline $\begin{array}{l}\text { Receita Total da Produção de Soja (excluídos valores adicionais } \\
\text { e bonificações) em 2014/2015 }\end{array}$ & Métrica & RT \\
$\begin{array}{l}\text { Custo Total com Arrendamento de Máquinas agrícolas em } \\
\text { 2014/2015 }\end{array}$ & Métrica & CTM \\
$\begin{array}{l}\text { Receita Total com bonificação do Programa de Biodiesel em } \\
2014 / 2015\end{array}$ & Métrica & RTB \\
$\begin{array}{l}\text { Receita Total de Fontes não Agrícolas em 2015 } \\
\begin{array}{l}\text { Contratação de CPR como forma de financiamento em } \\
2014 / 2015\end{array}\end{array}$ Métrica & RNA \\
\hline
\end{tabular}

Fonte: Elaboração do autor, 2017.

${ }^{1} \mathrm{Em}$ todas as variáveis foi utilizado o logaritmo natural obtido a partir de seus valores monetários $(R \$)$. Foi atribuído valor zero para observações que não continham valores.

$$
I I A F_{i}=\alpha_{1}+\alpha_{2} R T_{i}+\alpha_{3} C T M_{i}+\alpha_{4} R T B_{i}+\alpha_{5} R N A_{i}+\alpha_{6} V C P R_{i}+\varepsilon_{i}
$$

Sendo:

$\varepsilon_{i}=$ Vetor de erros aleatórios;

Para testar a adequação do modelo aos pressupostos dos modelos de regressão, foi realizado os testes: i) de Heterocedasticidade, com o teste normalizado de Breusch-Pagan; ii) Multicolinearidade, com o teste de VIF (Variance Inflation Factor) e; iii) Autocorrelação, com o teste Breusch-Godfrey de ordem 1. 


\subsection{Tratamento dos dados}

Para permitir a comparação de dados e informações representados em valores monetários em séries temporais, todos valores foram atualizados para dezembro de 2016 com base no Índice Geral de Preços - Disponibilidade Interna (IGP-DI), mantendo um único momento no tempo como base para comparação.

O lucro da atividade produtiva foi mensurado através das informações disponibilizadas pelos produtores rurais familiares sobre a produção agrícola. A receita total com a venda de soja foi obtida pela multiplicação da quantidade produzida de soja (em sacas) pelo preço médio recebido (em reais por saca). A este valor foi somado a receita com a bonificação recebida pela venda ao programa de biodiesel (aos produtores que realizaram este tipo de contrato).

O custo total de produção é composto por três componentes: i) custo de produção da lavoura, contemplando os insumos utilizados, como sementes, fertilizantes, defensivos, combustível, mão de obra e outras despesas da safra; ii) custo com arrendamento de terra, para os produtores que arrendam terra e; iii) custo com prestação de serviço de mecanização, para os produtores que contrataram serviços de maquinário, principalmente a colheitadeira. E o lucro foi calculado pela subtração da receita total na atividade pelo custo total obtido.

\section{RESULTADOS E DISCUSSÃO}

\subsection{Ambiente e arranjo institucional na produção familiar}

Ao analisar o ambiente institucional da produção de soja na agricultura familiar, é possível notar a presença de instituições formais de incentivo ao desenvolvimento, como o Programa de Biodiesel com o Selo Combustível Social, que fomenta a participação da agricultura familiar neste setor; a Reforma Agrária, com a redistribuição de terras, fundando os projetos de Assentamentos; e o Pronaf, como linha de fomento ao crédito e modernização da produção.

Outras instituições criam mecanismos de regulação que impactam diretamente na decisão de produção. A legislação ambiental recai sobre os produtores rurais reduzindo a área disponível para cultivo, devido a necessidade de conservação de áreas de reserva legal, áreas de preservação permanente. Seguir a legislação é necessário tanto para evitar multas ambientais, como também para poder obter acesso a diversos programas públicos, como o próprio crédito rural. Este último foi relatado por alguns produtores rurais como uma das obstruções para poder obter o Pronaf.

A cadeia produtiva ainda possui alguma forma de influência sobre o ambiente institucional, dado a sua importância econômica nacional. Subsídios e renegociações de dívidas -sejam do crédito rural, previdenciárias ou fiscais- são formas pela qual o governo auxilia a manutenção das atividades quando o setor é impactado. Tais mudanças institucionais normalmente têm origem com as pressões políticas exercidas pelos agricultores, sindicatos e associações ligadas a soja. A Figura 1 representa como o ambiente institucional produz efeitos sobre os agentes, levandoos a desenvolverem estruturas de governança -arranjo institucional para lidar com os custos de transação associados as instituições. 
Figura 1 - Produção de soja na agricultura familiar: influência das instituições, mecanismos institucionais e difusão da inovação.

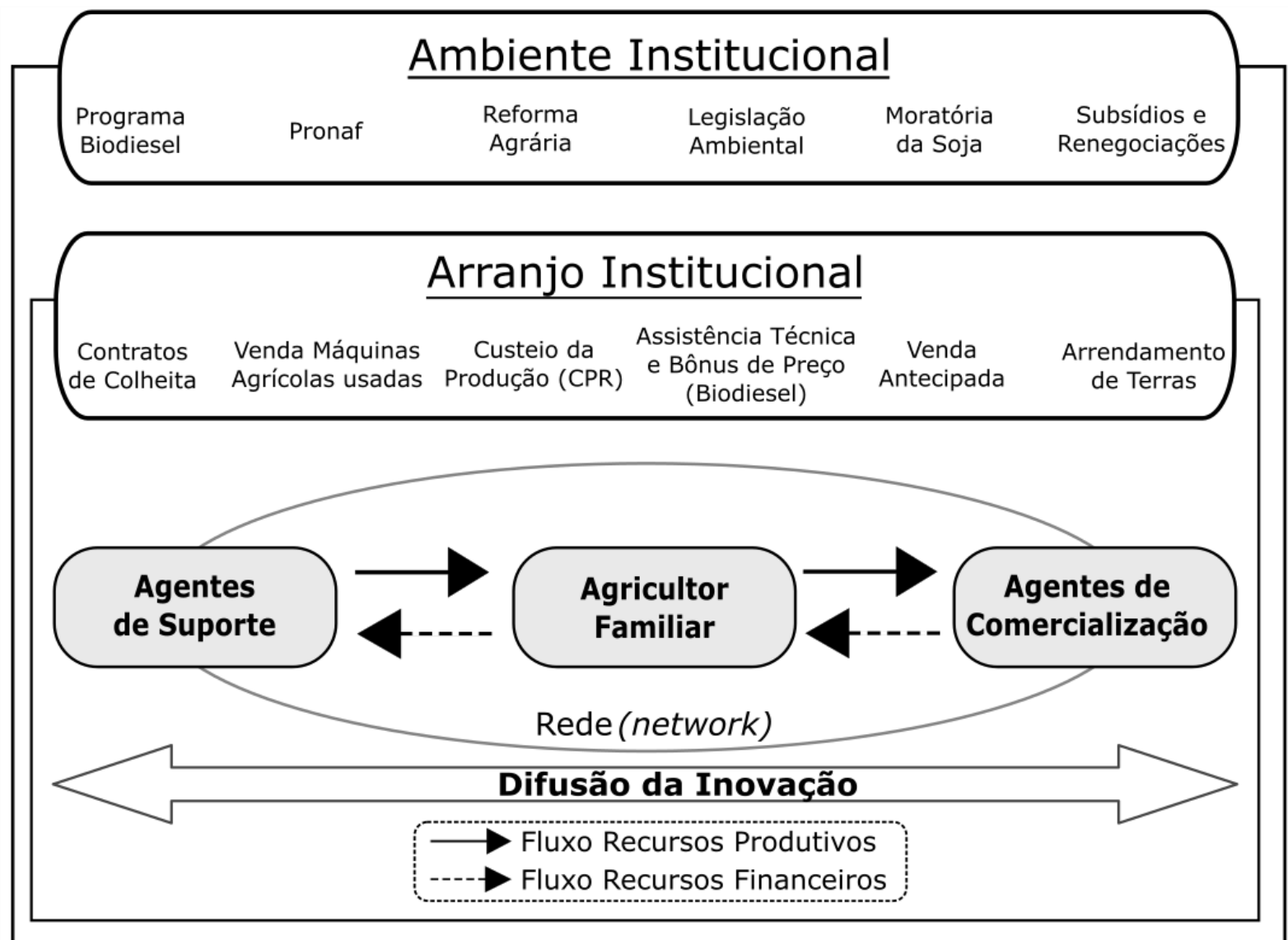

Fonte: Elaboração do autor a partir dos dados da pesquisa.

Estudos apontam que a produção agrícola pode pressionar a questão ambiental na Amazônia, direta ou indiretamente (FEARNSIDE, 2001; GOLLNOW et al., 2018). Diante do cenário onde a soja passa a ser uma atividade que ameace a preservação da Amazônia (a região de estudo se localiza no Bioma Amazônia), a cadeia produtiva também sofre impactos com esta realidade. Neste sentido, 0 desenvolvimento de mecanismos de enforcement-capacidade do agente em forçar o cumprimento de uma lei ou norma- além da própria capacidade de comando e controle do estado são necessários. A própria cadeia produtiva se organizou para colocar em prática a Moratória da Soja, na qual as empresas comercializadoras se comprometem a não adquirir soja de agricultores que desmataram áreas após 2008 de forma ilegal (GIBBS et al., 2015; RUDORFF et al., 2011). Impedir a comercialização do produto por desvios ambientais implica tanto uma restrição de mercado (não ter condições de negociação) como a não operação em contratos fundamentais como a CPR (que provê recursos essenciais de curto prazo).

Todos estes mecanismos são inovações institucionais que são difundidos pela rede (network) estabelecida entre os agentes de suporte -fornecem insumos, crédito, conhecimento, equipamentos, serviços, os agricultores familiares e os agentes de comercialização -recebem a soja, produto, no qual irão dar destino econômico, mediante o pagamento aos agricultores-. Neste contexto, a inserção dos agricultores familiares neste mercado permite o uso produtivo da terra, favorecendo o desenvolvimento rural ao gerar renda no campo. Entretanto, ainda é necessário 
explorar em qual contexto, tais agricultores familiares estão inseridos, pois a forma de inserção no mercado de soja pode ser restritiva para alguns grupos.

\section{2 Índice de Inovação da Agricultura Familiar}

A idade média dos membros familiares que responderam o questionário era de 48 anos. Em relação a escolaridade, 59,7\% completou até o ensino fundamental, $36,1 \%$ concluíram o ensino médio e apenas $2,8 \%$ o ensino superior. A grande maioria mora na própria propriedade rural $(80,5 \%)$ em que realiza o cultivo da soja.

Para avaliar os mecanismos de inserção da agricultura familiar na produção de soja, foi conduzida a AFE. Para verificar se existe correlação suficiente entre as variáveis para aplicação da AFE o teste KMO foi calculado e obteve-se o valor de 0,581, superior ao valor mínimo recomendado para a AFE de 0,5 (HAIR et al., 2014). O Teste de esfericidade de Bartlett também se mostrou significativo (Qui-quadrado de 245,484, 45 graus de liberdade, p-valor menor que 0,01).

Para a extração dos fatores foi utilizado o método dos componentes principais. O primeiro componente possui a maior explicação da variância, e cada componente em sequência explica uma quantidade menor da variância em relação ao componente anterior, tendo como base a ortogonalidade entre eles.

Somente autovalores superiores a 1,0 foram considerados, valores menores indicam que o fator não é capaz de explicar a variância de pelo uma variável, sendo descartados. O resultado foi a seleção de quatro fatores que explicam $72,40 \%$ da variância total com o modelo a partir de onze variáveis selecionadas. Este resultado foi obtido com a matriz de componentes rotacionadas pelo método VARIMAX (mantendo a ortogonalidade). O primeiro fator explicou $27,70 \%$ da variância total, comprovando a capacidade do método em garantir ao primeiro componente maior capacidade de explicação da variância total. Os demais fatores explicaram 15,40\%, $14,90 \%$ e $14,40 \%$ respectivamente.

Foi avaliada a comunalidade de cada variável para verificar a necessidade de remover alguma da análise. Todas apresentaram valor superior a 0,5, o que garante sua adequação ao modelo proposto (HAIR et al., 2014). Como próximo passo foi calculado a matriz de cargas fatoriais rotacionadas para identificar em qual fator cada variável deve ser alocada (Tabela 3). Para isto, foi verificado qual a carga fatorial, para cada variável em cada fator, possui o valor absoluto mais alto. 
Tabela 3 - Matriz de cargas fatoriais rotacionadas (somente o maior valor absoluto foi apresentado).

\begin{tabular}{|c|c|c|c|c|c|}
\hline \multirow[b]{2}{*}{ Variáveis } & \multicolumn{4}{|c|}{ Fatores } & \multirow[b]{2}{*}{ Comunalidade } \\
\hline & $\begin{array}{c}1- \\
\text { "Recursos } \\
\text { produtivos" }\end{array}$ & $\begin{array}{l}2- \\
\text { "Rendas não } \\
\text { agrícolas" }\end{array}$ & $\begin{array}{c}3- \\
\text { "Contratos } \\
\text { institucionais" }\end{array}$ & $\begin{array}{c}4- \\
\text { "Instrumentos } \\
\text { de apoio" }\end{array}$ & \\
\hline LS & 0,814 & & & & 0,682 \\
\hline ID & & 0,848 & & & 0,725 \\
\hline AT & 0,951 & & & & 0,921 \\
\hline MA & & & & 0,812 & 0,710 \\
\hline $\mathrm{CP}$ & & & & 0,643 & 0,607 \\
\hline BIO & & & 0,755 & & 0,698 \\
\hline RNA & & 0,783 & & & 0,662 \\
\hline CPR & & & 0,906 & & 0,844 \\
\hline VA & & & & 0,549 & 0,594 \\
\hline $\mathrm{RP}$ & 0,861 & & & & 0,799 \\
\hline
\end{tabular}

Fonte: Elaboração do autor a partir dos dados da pesquisa.

O Fator número 1 passa agora a ser denominado de "Recursos produtivos", contendo as variáveis Lucro na Safra 2014/2015 (LS); Área total plantada de soja em 2014/2015 (AT) e; Recursos próprios para custeio da safra 2014/2015 (RP). O lucro obtido na safra é correlacionado com a área total plantada e tende a crescer a medida em que a área produtiva for ampliada. Por sua vez, a ampliação da área plantada exige mais recursos para custeio, o que leva ao produtor a investir mais capital próprio na atividade com a aquisição de insumos produtivos. Juntamente com a CPR, o capital próprio (29,9\% do custo de produção foi coberto com capital próprio) é uma fonte (não contratual, pois depende apenas da disponibilidade interna dos produtores) de recursos de custeio.

O Fator 2 ficou composto pelas variáveis Idade (ID) e Total das receitas não agrícolas em 2015 (RNA), sendo denominada "Rendas não agrícolas". Neste fator fica evidenciado a correlação entre a idade e a existência de fontes de renda externas a propriedade, devido principalmente ao predomínio de aposentadorias no meio rural em famílias que possuem membros com idade mais avançada. Também deixa claro que a idade não é uma variável que influência na produtividade.

O Fator 3, composto pelas variáveis: fornece para o programa de biodiesel (BIO) e contratou 'pacote' (CPR), foi denominado "Contratos institucionais". Este fator descreve alguns dos contratos que são aderidos pelos produtores rurais e se correlacionam. A produção de biodiesel favorece a produção por gerar renda adicional as famílias através do bônus de preço, negociado com as indústrias, e garante a venda da produção de soja a esta empresa. A CPR permite a realização da safra através da negociação antecipada de parte da produção em troca de recursos para custeio. Tais contratos são negociados no arranjo estabelecido entre produtores familiares e empresas agrícolas, e são inovações institucionais por permitirem a consolidação da atividade em unidades desprovidas de capital e incrementarem a renda familiar pelo adicional de preço, embora vinculando a venda futura a um preço determinado.

Por fim o fator 4, descrito como "Instrumentos de apoio" ficou composto pelas variáveis: Contratou Pronaf Mais Alimentos (MA); possui colheitadeira própria (CP) e valores de vendas antecipadas (VA). Os recursos tecnológicos, como máquinas e 
equipamentos (próprios ou adquiridos por financiamento) permitem maior controle sobre a produção e ampliação da renda. A colheitadeira própria, embora amplie o valor do investimento na propriedade, pode reduzir o custo da produção em relação ao pagamento de serviços de terceiros. As vendas antecipadas podem ser consideradas inovações institucionais que permitem a agricultura familiar garantir a comercialização de sua produção, reduzindo riscos de preços e de demanda no mercado.

Obtida as cargas fatoriais foi possível estimar os escores fatoriais por meio do método de Thomson. Os escores fatoriais são os coeficientes para cada observação em cada fator. Neste trabalho os escores foram utilizados para o desenvolvimento de um índice tecnológico e de renda dos produtores familiares pesquisados. Para este fim, os escores foram normalizados em uma escala de 0 à 1 para cada fator extraído.

Dentro desta escala normalizada foi possível obter um índice pela soma de cada escore normalizado para cada observação, dividido pelo número de fatores (quatro). O resultado obtido mede o grau tecnológico e de geração de renda dos agricultores familiares através de sua adesão aos contratos e estratégias desenvolvidas no arranjo institucional estabelecido. Quanto maior o valor do índice obtido, maior o grau de adesão as inovações institucionais e maior a capacidade de geração de renda da propriedade. Em contrapartida, quanto menor o índice, menor a capacidade geração de renda e adesão as inovações institucionais.

A partir dos resultados obtidos com o índice foi possível classificar os produtores rurais em três níveis (baixa, média e alta) de adesão tecnológica e capacidade de geração de renda. A Tabela 4 traz uma distribuição de frequência dos agricultores nesta escala. Importante destacar que as práticas agrícolas são muito próximas ou muito bem assimiladas entre os produtores rurais. Em todos os casos foi confirmado práticas como, plantio direito, rotação de cultura (principalmente com o milho), utilização de adubos químicos, trabalhos mecanizados (plantio, tratos culturais e colheita). A principal fonte de inovação é, portanto, institucional.

Tabela 4 - Distribuição de frequência do IIAF e características por nível.

\begin{tabular}{cccccc}
\hline \multirow{2}{*}{$\begin{array}{c}\text { Nível } \\
\text { IIAF }\end{array}$} & Frequência & $\%$ & \multicolumn{3}{c}{ Características do Nível de IIAF } \\
\cline { 4 - 6 } & & & $\begin{array}{c}\text { Colheitadeira } \\
\text { própria }\end{array}$ & $\begin{array}{c}\text { Área média da } \\
\text { propriedade (ha) }\end{array}$ & $\begin{array}{c}\text { Lucro Médio } \\
\text { (R\$)* }\end{array}$ \\
\hline Baixa & 12 & $16,7 \%$ & $33,3 \%$ & 70,42 & $43.945,82$ \\
Média & 55 & $76,4 \%$ & $67,27 \%$ & 132,49 & $96.104,94$ \\
Alta & 05 & $6,9 \%$ & $100 \%$ & 270,80 & $97.331,82$ \\
\hline
\end{tabular}

Fonte: Elaboração do autor a partir dos dados da pesquisa.

* Valores atualizados para dezembro/2016.

Os resultados demonstram que a maior parte dos produtores rurais se concentram em IIAF médio (76,4\% dos produtores rurais). Embora existam diversos mecanismos institucionais presentes, nem todos os agricultores aderem a todos simultaneamente, concentrando o IIAF no nível médio. Em relação ao lucro na atividade, observou-se que ele varia entre uma média de 49 e 110 salários mínimos anuais (salário mínimo de $\mathrm{R} \$ 880,00$, vigente em 2016, momento da pesquisa). 
A contratação de serviço de maquinários é realizada por $36,1 \%$ dos produtores rurais, os demais possuem colheitadeira própria. Este montante indica a quantidade de produtores que ainda não dispõe de tal equipamento próprio na propriedade, necessitando desenvolver alternativas (institucionais) para suprir a necessidade, sendo a principal forma a elaboração de contratos de serviço de colheita.

Ainda sobre investimento na produção, apenas $37,5 \%$ dos agricultores familiares afirmaram ter ou já ter tido acesso ao Pronaf Mais Alimentos. Esta linha de crédito permite o investimento na atividade com taxas subsidiadas, sendo um mecanismo de desenvolvimento da produção. No entanto, esta prática ainda não está totalmente difundida no arranjo institucional, sendo a dificuldade de obtenção de crédito um dos principais motivos apontados pelos produtores rurais. Dentre as causas que dificultam o acesso, são citadas: a exclusão das linhas de créditos por questões documentais, como regularidade ambiental (da propriedade ou do assentamento), a indisponibilidade de garantias para contrapartida do financiamento, baixo nível de informação e conhecimento sobre o Pronaf, a condição de acesso à terra (assentado) e respectivo grupo na Declaração de Aptidão ao Pronaf (DAP).

A baixa adesão ao Pronaf reduz a capacidade de investimento, ampliando a necessidade dos produtores em encontrarem fontes alternativas de financiamento, que acabam sendo solucionadas pela cadeia produtiva, como a CPR. 0 desenvolvimento de contratos e métodos alternativos de uso de maquinário (arrendamento em substituição a aquisição) permitem a produção familiar pela substituição do investimento em capital por custo de produção (pagamento de serviços de colheita).

Os contratos de venda antecipada, embora tenham movimentado 34,9\% da receita da soja dos pequenos produtores na safra 2014/2015, não estão completamente difundidos no arranjo institucional. Este tipo de contrato ocorreu com $68,1 \%$ dos produtores pesquisados, portanto ainda existe um potencial maior de expansão. Alguns produtores, mesmo conhecendo os contratos, não o adotam por sua própria forma de gestão, preferindo negociar preços após a safra. Neste tipo de público existem restrições à adoção de contratos, que não necessariamente estão ligados ao desconhecimento, mas a percepção de vantagem do agricultor em outros métodos de negociação (expectativa de preços futuros mais elevados).

O mesmo ocorre para o fornecimento de matérias-primas para o biodiesel. Em Mato Grosso a produção de soja para o biodiesel conta com adicionais de preços e apoio das usinas aos agricultores, haja visto o ganho de vantagens em leilão (RODRIGUES; SILVA; SILVA, 2019). Embora seja um importante mecanismo para geração adicional de renda na agricultura familiar, apenas 43,06\% dos agricultores familiares forneceram para o programa na safra 2014/2015. Esta adesão depende tanto do agricultor familiar ser um produtor de oleaginosas quanto também da empresa ou usina adquirir do produtor. Dado o estabelecimento de contratos, 0 produtor firma o compromisso de entrega para uma determinada empresa agrícola, entretanto, para a negociação ser concretizada, ambos devem honrar seus compromissos. Este risco de não cumprimento é reduzido a medida em que o contrato vai se repetindo safra após safra, pois as partes passam a ter confiança caso os itens contratuais acordados sejam consolidados. Embora a especificidade da soja seja baixa, a usina busca realizar contratos para programar a sua produção, reduzindo a necessidade de estoques e de capacidade ociosa na planta. 
A concentração de agricultores familiares com IIAF médio demonstra a situação de que alguns recursos produtivos e contratos estão presentes na atividade, enquanto outros já não são observados. O tamanho médio da propriedade deste grupo também está acima do grupo de IIAF baixo, mas é menor do que o grupo de IIAF alto. Com reflexo, o lucro, que é tanto mais alto quanto maior é a área produzida (pelo efeito de escala da soja). O lucro médio obtido na safra 2014/2015 entre os diversos grupos de IIAF demonstra que, mesmo em níveis menores de adesão tecnológica, a soja se demonstra uma atividade rentável.

\subsection{Determinantes da inovação}

Com o objetivo de verificar quais variáveis podem interferir no IIAF foi realizado uma regressão linear por meio de Mínimos Quadrados Ordinários (MQO) conforme foi demonstrado na Equação 3. O modelo propõe identificar as características dos produtores ou da produção que interferem no nível tecnológico e produtivo da agricultura familiar produtora de soja. Os resultados obtidos estão contidos na Tabela 5.

Tabela 5 - Resultados da regressão por MQO. Variável dependente: IIAF.

\begin{tabular}{ccc}
\hline Variável & Coeficiente & Estatística t \\
\hline Intercepto & $-0,319275$ & $-2,032^{*}$ \\
RT & 0,051214 & $4,067^{* * *}$ \\
CTM & $-0,008756$ & $-3,986 * * *$ \\
RTB & 0,011455 & $5,235^{* * *}$ \\
RNA & 0,010572 & $4,189 * * *$ \\
VCPR & 0,009500 & $4,310 * * *$ \\
\hline $\mathbf{R}^{\mathbf{2}}$ & 0,6447 & \\
F & $23,96 * * *$ & \\
\hline
\end{tabular}

Fonte: Elaboração do autor a partir dos dados da pesquisa.

Níveis de significância: '***' 0,001 ; $^{* * *} 0,01$; $^{\prime *}$ ' 0,05

Para verificar a adequação deste modelo foram realizados os testes estatísticos necessários. $O$ teste normalizado de Breusch-Pagan não detectou presença heterocedasticidade ( $p$-valor $=0,1652$ ). Não foi evidenciado autocorrelação entre os termos de erro pelo teste Breusch-Godfrey ( $p$-valor $=0,7733$ ). Também não foi detectada a presença de multicolinearidade entre as variáveis do modelo pelo teste de Fator de Inflação da Variância (em inglês, Variance Inflation Factor-VIF), todas variáveis apresentaram valor abaixo de 10. O teste $\mathrm{F}$ calculado demonstrou significância geral da regressão ( $p$-valor $<0,001$ ).

A variável Receita Total da Produção de Soja na safra 2014/2015 (RT) demonstrou-se significativa e positiva. É possível relacionar este resultado com a economia de escala na produção de soja. $O$ incremento da receita total entre produtores, para uma mesma safra, ocorre principalmente pelo aumento da área produzida. As propriedades que cultivam até 100 hectares possuem uma receita média de $R \$ 2.479,26 /$ hectare; entre 100 e 200 hectares apresentaram uma diferença pequena (média de $\mathrm{R} \$ 2.454,25 /$ hectare); acima de 200 hectares a receita 
média aumentou para $\mathrm{R} \$ 2.744,48 /$ hectare. No geral, o coeficiente de variação para a receita por hectare é de $23,8 \%$.

A limitação de terra na agricultura familiar torna às propriedades maiores consequentemente mais rentáveis, como ficou correlacionado também na análise fatorial (Fator 1 - Recursos Produtivos), pois a mudança na receita é reduzida, logo o ganho financeiro deve ser conquistado pelo incremento da produção total, elevando-se a área cultivada. Dado o pacote tecnológico vigente, a produtividade em propriedades de soja, tanto pequenas como grandes, são semelhantes - a média de produtividade para o estado de Mato Grosso foi de 51,9 sacas por hectare nas safras 2014/2015 (IMEA, 2015, 2016), enquanto que para os agricultores deste estudo a média ficou em 53,71 sacas -. Portanto, economias de escala ainda são importantes na produção de soja familiar, enquanto as inovações institucionais propiciam a redução da escala necessária para viabilizar a produção.

Dado a limitação em extensão dos lotes, os agricultores familiares que desenvolvem a soja tendem a expandir sua produção à medida que obtém resultados satisfatórios com a finalidade de ampliar a renda familiar. Para tal, arrendam propriedades vizinhas (assentadas ou não), mesmo continuando na condição de assentado. Esta prática ocorre principalmente em assentamentos, no qual a extensão do lote é o principal limitante, consequentemente os contratos são estabelecidos informalmente, dado a ilegalidade do ato, mas são respeitados entre os produtores. Este tipo de contrato não foi detalhado ao longo do estudo e pode ser objeto de estudos futuros. Os arrendantes acabam por aderir a tal situação por não terem as condições suficientes para praticar a produção de soja. Evidencia-se uma limitação dos mecanismos institucionais em contornar o paradigma tecnológico.

A variável Custo com Arrendamento de Máquinas agrícolas em 2014/2015 (CTM) também se demonstrou significante, entretanto negativa. A adoção tecnológica proposta pelo IIAF considerou a existência de máquinas agrícolas próprias como principal forma de realização da colheita. Os contratos de prestação de serviço são soluções desenvolvidas que permitem a substituição do investimento por custo. Esta medida acaba levando a uma certa redução do lucro da atividade produtiva devido à elevação do custo.

Em média, propriedades que arrendaram máquinas agrícolas na safra 2014/2015 apresentaram um custo total por hectare 1,9\% maior que propriedades que possuem máquinas próprias. Os contratos possibilitam que a agricultura familiar desenvolva a produção de soja que, sem os contratos, somado as dificuldades e inviabilidade de aquisição de maquinário, seria impossível. Portanto, embora a prestação de serviço reduza as margens de lucro do produtor, ela torna possível a produção agrícola.

Como esperado, a Receita Total com bonificação do Programa de Biodiesel em 2014/2015 (RTB) se mostrou significativa e positiva. O recebimento de receitas adicionais com a produção de soja (como o caso do Biodiesel, com o adicional contratual de preço por saca) se demonstra um mecanismo institucional importante de fomento à produção. O produtor beneficiado com tal programa, além de ampliar a margem de lucro da produção e consequentemente a renda familiar, também permite o reinvestimento destes recursos na produção agrícola.

As receitas não agrícolas (RNA) foram fontes de renda que não estão vinculadas a atividade agrícola da propriedade rural. A principal fonte de renda identificada nas famílias foi a aposentadoria, presente em $25 \%$ das propriedades 
amostradas. Esta variável também se mostrou significativa e positiva por possuir alta correlação com o Fator "Rendas não agrícolas". A baixa presença de trabalho assalariado entre os produtores rurais demonstra que a atividade agrícola de produção de commodities vem se mostrando promissora e rentável, incentivando que os membros da família permaneçam com esta produção como foco.

Em relação as fontes de recursos para custeio, o recurso obtido com a Cédula de Produto rural -"pacote"- (VCPR) se mostrou significativo e positivo. A CPR permite à agricultura familiar a obtenção de recursos financeiros para custeio da produção através da promessa de entrega futura do produto, esta fonte de recursos supre necessidades de capital existentes na pequena produção familiar. A alta adesão aos produtores familiares (47,08\% do custo da safra 2014/2015 foi liquidado com esta fonte de recursos) demonstra a importância deste tipo de contrato.

Os contratos institucionais existentes no arranjo produtivo, como a venda para o biodiesel e a CPR, se mostraram correlacionados na AFE. Estes contratos reduzem alguns riscos ao estabelecerem as regras da transação entre os agentes, para a agricultura familiar ainda atua como um incentivo à produção de commodities.

Embora o custo médio de produção seja menor com a maior aplicação de capital próprio, é importante ressaltar que a maior parte da agricultura familiar opera com a contratação de CPR (79,2\% das propriedades amostradas), pois os custos produtivos normalmente são muito elevados para a estrutura de capital existente na pequena produção familiar. $O$ arranjo institucional estabelecido permite que a agricultura familiar consiga recursos privados para suprir suas necessidades, sendo o contrato da CPR um dos principais. A adesão a tal instrumento, além de suprir a necessidade de financiamento do agricultor, também facilita a organização da produção e transação entre os agentes: previsão de entrega, quantidade a ser comercializada, qualidade do produto, entre outras características possíveis de previsão.

\section{CONCLUSÃO}

O objetivo deste estudo foi analisar as inovações institucionais que permitem a inserção da agricultura familiar do Norte de Mato Grosso na cadeia produtiva da soja. Identificou-se que tal atividade é capaz de gerar renda para a agricultura familiar de forma satisfatória, mesmo em áreas de cultivo reduzidas. Para viabilizar a atividade, os agricultores familiares aderem a mecanismos contratuais que permitem reduzir a necessidade de capital. A substituição da aquisição de máquinas agrícolas novas pela contratação de serviços de colheita reduz a exigência de capital a longo prazo. As necessidades financeiras de curto prazo são supridas pela adesão à CPR com as tradings, com pagamento futuro em produto (soja).

Entretanto, o modelo tradicional de produção, baseado na grande exploração agrícola, alta aplicação de capital por unidade de área e investimento em ativos (máquinas e implementos) e mercado fortemente atrelado as indústrias, que ainda deixa suas marcas na produção familiar. As mesmas instituições que tornam possível a operação em pequena escala também leva a uma pressão para o incremento de área cultivável para fins de incremento da renda, pois a receita por hectare não varia fortemente entre as propriedades (coeficiente de variação para a receita por hectare de $23,8 \%$ ). 
Quanto as políticas públicas, o Pronaf se mostrou insuficiente pois um número reduzido de agricultores (37,5\%) tem ou já teve acesso ao crédito. O Programa de Biodiesel atua elevando a renda de algumas famílias, porém ainda possui abrangência limitada à alguns produtores rurais (43\% dos agricultores tiveram acesso a este mercado).

Embora se demonstre promissora a inserção no mercado de alguns produtores familiares mais tecnificados, a produção se soja ainda necessita ser mais bem detalhada para verificar a sustentabilidade da produção. Trabalhos futuros podem investigar os efeitos que a expansão da sojicultura em pequenas propriedade teria sobre a questão ambiental e de saúde humana.

\section{REFERÊNCIAS}

ABRAMOVAY, R. Paradigmas do Capitalismo Agrária em Questão. Campinas: Hucitec, 2007.

ADENLE, A. A.; MANNING, L.; AZADI, H. Agribusiness innovation: A pathway to sustainable economic growth in Africa. Trends in Food Science \& Technology, v. 59, p. 88-104, 2017.

AMARAL, M. C. F. et al. Management and technological practices in Amazonian fish farms: A case study in the Southeast of Pará. Aquaculture, v. 507, p. 183-189, 2019.

BARTHOLOMEW, D. J. et al. Analysis of Multivariate Social Science Data. 2 ed ed. Boca Raton: Taylor \& Francis Group, 2008.

BELIK, W.; PAULILLO, L. F. O Financiamento da produção agrícola brasileira na década de 90: ajustamento e seletividade. In: LEITE, S. P. (Ed.). . Políticas públicas e agricultura no Brasil. Porto Alegre: Editora da UFRGS, 2009. p. 97122.

BERGER, M.; ORTEGA, F. Poblaciones expuestas a agrotóxicos: autoorganización ciudadana en la defensa de la vida y la salud, Ciudad de Córdoba, Argentina.

Physis: Revista de Saúde Coletiva, v. 20, n. 1, p. 119-143, 2010.

CEPEA/ESALQ. PIB do agronegócio brasileiro de 1996 a 2018. Disponível em: $<$ http://www.cepea.esalq.usp.br/upload/kceditor/files/PIB Agronegócio_Cepea_1996_2017.xIsx>. Acesso em: 9 out. 2018.

CONAB. Séries Históricas - Soja. Disponível em: <https://www.conab.gov.br/infoagro/safras/serie-historica-das-safras?start=30>. Acesso em: 8 maio. 2020.

\section{DEFRIES, R. et al. Deforestation Drive by Urban Population Growth and} Agricultural Trade in the Twenty-First Century. [s.I: s.n.]. v. 3

DUCHELLE, A. E. et al. Linking Forest Tenure Reform, Environmental Compliance, and Incentives: Lessons from REDD+ Initiatives in the Brazilian Amazon. World Development, v. 55, p. 53-67, mar. 2014. 
ESTABROOK, R.; NEALE, M. A Comparison of Factor Score Estimation Methods in the Presence of Missing Data: Reliability and an Application to Nicotine Dependence.

Multivariate behavioral research, v. 48, n. 1, p. 1-27, 1 jan. 2013.

FEARNSIDE, P. M. Soybean cultivation as a threat to the environment in Brazil.

Environmental Conservation, v. 28, n. 1, p. 23-38, 2001.

GIBBS, H. K. et al. Brazil's Soy Moratorium. Science , v. 347, n. 6220, p. 377-378, 23 jan. 2015.

GOLLNOW, F. et al. Property-level direct and indirect deforestation for soybean production in the Amazon region of Mato Grosso, Brazil. Land Use Policy, v. 78, p. 377-385, 2018.

GOULSON, D. et al. Bee declines driven by combined stress from parasites, pesticides, and lack of flowers. Science, v. 347, n. 6229, 27 mar. 2015.

HAIR, J. F. et al. Multivariate Data Analysis. 17 ed ed. Harlow: Pearson, 2014.

IBGE. Censo Agropecuário. Disponível em: <www.ibge.gov.br>. Acesso em: 30 mar. 2018.

IBGE. Censo Agropecuário 2017. Disponível em:

<https://sidra.ibge.gov.br/pesquisa/censo-agropecuario/censo-agropecuario-2017>. Acesso em: 31 mar. 2020.

IBGE. Sistema IBGE de Recuperacao automatica-SIDRA. Disponível em: <http://www.sidra.ibge.gov.br/>. Acesso em: 17 abr. 2020.

IMEA. Quinta Estimativa da Safra de Soja - 2014/15. Disponível em: <http://www.imea.com.br/upload/publicacoes/arquivos/R404_5a_Estimativa_de_sa fra_de_Soja_2014-15__23-04-2015_AO.pdf >. Acesso em: 31 out. 2017.

IMEA. Sexta Estimativa da Safra de Soja - 2015/16. Disponível em: <http://www.imea.com.br/upload/publicacoes/arquivos/R404_6_Estimativa_Soja_saf ra_2015-16_16-04_29.pdf>. Acesso em: 31 out. 2017.

KLERKX, L.; AARTS, N.; LEEUWIS, C. Adaptive management in agricultural innovation systems: The interactions between innovation networks and their environment. Agricultural Systems, v. 103, n. 6, p. 390-400, jul. 2010.

PLOEG, J. D. VAN DER et al. Rural Development: From Practices and Policies towards Theory. Sociologia Ruralis, v. 40, n. 4, p. 391-408, 2000.

RODRIGUES, M.; SILVA, F. D. DA S.; SILVA, D. C. C. Family Farming and Biodiesel: rural development in Central-Western Brazil. Novos Cadernos NAEA, v. 22, n. 3, p. 25-44, 2019.

RUDORFF, B. F. T. et al. The soy moratorium in the Amazon biome monitored by remote sensing images. Remote Sensing, v. 3, n. 1, p. 185-202, 2011. 
SANTANA, A. C. Índice de desempenho competitivo das empresas de polpa de frutas do Estado do Pará. Revista de Economia Rural, v. 45, n. 03, p. 749-775, 2007. TIMM, N. H. Applied Multivariate Analysis. New York: Springer, 2002.

VANDER VENNET, B.; SCHNEIDER, S.; DESSEIN, J. Different farming styles behind the homogenous soy production in southern Brazil. The Journal of Peasant Studies, v. 43, n. 2, p. 396-418, 3 mar. 2016.

WESZ, V. J. La filiera della soia nell'America del Cono Sud: dinamiche, processi e attori. Rivista di Economia Agraria, v. 71, n. 1, p. 25-45, 2016. 